\title{
Mating capacity of male deer mice (Peromyscus maniculatus bairdi) copulating with successive females
}

\author{
DONALD A. DEWSBURY \\ University of Florida, Gainesville, Florida
}

\begin{abstract}
Each of 30 male deer mice, Peromyscus maniculatus bairdi, was provided the opportunity to copulate with 3 successive females for $1 \mathrm{~h}$ each. Male capacity was limited; only 22 males copulated with all 3 females and only 11 ejaculated with all 3 females. The amount of copulation decreased with successive females. The numbers of females pregnant in the three ordinal positions were 18,15 , and 8 , respectively. However, for the males that ejaculated with a female, there was no decrease in potency across successive females; the decreases that did occur overall were due to males that did not mate. For deer mice, unlike other species, even relatively sensitive methods reveal that males cease copulating before marked decreases in the potency of their ejaculates develop.
\end{abstract}

Evolutionary theorists have generally assumed that males are capable of producing so many sperm that male capacity is unlikely to be a limiting factor in the evolution of reproductive patterns and reproductive behavior (e.g., Darwin, 1871; Dawkins, 1976). More recently, however, it has become apparent that males have a limited capacity to produce ejaculates and that such limitations may have important implications for both male reproductive behavior and female choice of males as mating partners (Dewsbury, 1982; Nakatsuru \& Kramer, 1982). An understanding of the evolution of these patterns requires comparative analysis. It is therefore important that a foundation of empirical information be generated concerning the extent of limitations on male capacity for copulation and insemination of females, especially for species about whose reproductive behavior much is known.

There are many species differences related to male capacity. Although males of various species effectively cease copulating after a certain number of ejaculations and require some time to recover to baseline performance levels, the temporal parameters of these recovery processes vary greatly across species and strains (see Dewsbury \& Sawrey, 1984). There are species differences in withinepisode patterns as well. In most species studied to date, the number of sperm and other constituents of ejaculate decrease over successive ejaculations within a session (e.g., Adams \& Singh, 1981; Bakst \& Cecil, 1981). Furthermore, species appear to differ with respect to the relative fertility of the late ejaculates delivered by partially depleted males. In some species, such as laboratory rats (Austin \& Dewsbury, 1986; Toner \& Adler, 1985) and

This research was supported by Grant BNS-8520318 from the National Science Foundation. I thank Dianalee Deter and Joyce O. Sanders for doing vaginal smears. Address correspondence to Donald A. Dewsbury, Department of Psychology, University of Florida, Gainesville, FL 32611. golden hamsters (Huck \& Lisk, 1985a, 1985b), various measures of potency show decrements over successive ejaculations that are roughly parallel to the decrements in the parameters of ejaculates. For other species, however, such as rabbits (Adams \& Singh, 1981), there is no detectable decrement in potency despite substantial reductions in ejaculate contents. For such species it appears that males cease copulating before potency falls appreciably; males of such species have been termed "honest salesmen" (Halliday \& Houston, 1978).

Rested male deer mice deliver a mean of approximately four to five ejaculates to a female, with a rate of recovery to baseline levels for behavioral measures that is intermediate between those of laboratory rats and hamsters (Dewsbury, 1983). Although there are appreciable decrements in sperm counts with successive ejaculations, Dewsbury and Sawrey (1984) found no detectable effects on fertility with respect to either pregnancy initiation or sperm competition. The latter study was designed to assess the effectiveness of successive individual ejaculates; females thus received only one or two ejaculates from each male. An alternative procedure, which was used in the present study, is to permit the male to mate for a longer period with each female (see Huck \& Lisk, 1985a, 1985b). This may produce a more substantial depletion, more closely resemble the mating pattern in nature, and be more sensitive in detecting limitations on male fertility.

\section{METHOD}

The subjects were 30 male and 45 female deer mice, Peromyscus maniculatus bairdi, that were laboratory born and at least 90 days of age at the beginning of testing. The mice were maintained in a windowless, air-conditioned room on a reversed 16:8-h light:dark photoperiod of white fluorescent light with light onset at 1730 hours. They were housed in clear polycarbonate cages, measuring $48 \times 27 \times 13 \mathrm{~cm}$ for males and $29 \times 19 \times 13 \mathrm{~cm}$ for females. Wood shavings were provided for bedding, and water and Purina Laboratory Chow were continuously available. 
All animals were of proven fertility. Some had borne or sired litters in an earlier experiment. Others were pretested by pairing them for 15-20 days, with only those animals producing litters included in the study.

Tests were conducted in the home cages of the males. Behavioral patterns were recorded on an Esterline-Angus operations recorder supplemented with pencil and paper.

Daily vaginal smears were taken from all females, using tap water and a thin wire loop. Females were mated on the first day of vaginal estrus or proestrus. Tests were conducted only on days on which a sufficient number of females were available so that at least 2 females could be used in each of the three ordinal positions. Vaginal smears were continued after mating, and the results of the tests were categorized according to whether the female continued to cycle (returned to estrus in 7 days or less), became pseudopregnant (diestrus for 8 days or longer, generally 12-15 days), or became pregnant and delivered a litter.

Tests were initiated 2.5-3.5 h after light offset with the introduction of a female into a male's home cage. Pairs were permitted a variable time to initiate copulation; if copulation appeared unlikely, the first female was replaced with a second, and sometimes a third, female in similar vaginal condition. Once copulation was initiated, the pair was permitted to mate for a period of $1 \mathrm{~h}$. If active copulation was in progress and ejaculation appeared imminent, the time was extended by a few minutes. At the end of the 1-h period, the female was removed and replaced with a different, unmated female. The same procedure was followed. After $1 \mathrm{~h}$ of mating, the procedure was repeated. Thus, each male could mate with up to 3 females for $1 \mathrm{~h}$ each.

Each male was used once in the study. Females were used multiple times, with the constraint that they not be used more than once in each of the three ordinal positions.

There are three primary classes of events in the copulatory behavior of deer mice: mounts (without vaginal penetration), intromissions (with vaginal insertion and no sperm transfer), and ejaculations (with insertion and sperm transfer). These events are organized in "series," each of which begins with an intromission, ends with an ejaculation, and is separated from other series by a postejaculatory refractory period. After a number of organized series, males sometimes display a pattern of "long intromissions," which resemble ejaculations but appear to entail no sperm transfer and lack the temporal patterning of organized series (Dewsbury, 1979a). The standard measures of copulatory behavior defined by Dewsbury (1979a) were used.

\section{RESULTS}

The results are summarized in Table 1 . All males copulated and ejaculated with at least 1 female. Only 1 male failed to copulate with a second female; 6 males copu- lated but failed to ejaculate with a second female. Twentytwo males copulated with all 3 females, but only 11 ejaculated with all 3. One male copulated without ejaculation with the second female but ejaculated with the third.

The one male that failed to copulate with a second female passed up four successive females for a total period of 4,204 sec. Nine males passed up at least 1 second female, with a mean of 1.3 (range 1-3) females per male and a mean total delay of $1,709 \mathrm{sec}$, before copulating with a second female. Seven males that copulated with a second female failed with a third. They rejected a mean of 2.6 females (range 1-4) with a mean time of 3,604 sec. Nine of the males passed up at least 1 third female, with a mean of 1.8 females per male (range 1-3) and a mean delay of $2,033 \mathrm{sec}$, before copulating.

Males attained a mean of seven ejaculations and 109 intromissions per test. The amount of copulatory behavior fell off sharply with successive females. On average, nearly five of the seven ejaculations were with the first female, and less than one was with the third female. Analyses of variance revealed the decreases in the number of ejaculations and intromissions to be significant across females. A different pattern was shown for long intromissions, with a significant increase across females, consistent with their occurrence late in copulatory episodes (Dewsbury, 1979a).

Analyses of variance were used to compare the standard measures of copulatory behavior across the $3 \mathrm{fe}$ males. The only significant changes were for mount latency (time from the start of a test until the first mount or intromission), intromission latency (time from the start of a test until the first intromission), and postejaculatory interval (time from an ejaculation until the next intromission).

A total of 41 females out of a theoretical maximum (if all males had mated with 3 females) of 90 were successfully impregnated (46\%). Four males impregnated $3 \mathrm{fe}-$ males each; 6 males impregnated 2 females, 17 males impregnated 1 female, and 3 males impregnated none.

Table 1

Major Results of Study of Effects of Male Depletion

\begin{tabular}{|c|c|c|c|c|c|}
\hline \multirow[b]{2}{*}{ Measure } & \multicolumn{3}{|c|}{ Mean per Female $(\mathrm{F})$} & \multirow{2}{*}{$\frac{N}{\text { F1 F2 F3 }}$} & \multirow[b]{2}{*}{ Statistic } \\
\hline & F1 & F2 & F3 & & \\
\hline No. males copulating & 30 & 29 & 22 & & \\
\hline No. males ejaculating & 30 & 23 & 12 & & \\
\hline Mean no. ejaculations & 4.9 & 1.8 & 0.6 & 302922 & $F=109.56 \dagger$ \\
\hline Mean no. intromissions & 63.7 & 38.6 & 11.0 & 302922 & $F=18.13 \dagger$ \\
\hline Mean no. mounts & 22.2 & 17.1 & 13.5 & 302922 & $F=0.96$ \\
\hline Mean no. long intromissions & 0.1 & 1.0 & 1.9 & 302922 & $F=10.41 \dagger$ \\
\hline Mean mount latency $(\mathrm{sec})$ & 775.3 & 467.0 & 409.8 & 302922 & $F=3.55^{*}$ \\
\hline Mean intromission latency $(\mathrm{sec})$ & 966.1 & 500.2 & 459.1 & 302922 & $5.18 \dagger$ \\
\hline Mean first postejaculatory interval (sec) & 482.0 & 671.3 & 729.4 & 302312 & $F=5.09 *$ \\
\hline No. females pregnant (by all males) & 18 & 15 & 8 & & $Q=6.87 *$ \\
\hline $\begin{array}{l}\text { No. females pregnant (by males that } \\
\text { ejaculated with } 3 \text { females) }\end{array}$ & 7 & 7 & 7 & 111111 & 0.00 \\
\hline Mean gestation length (days) & 23.5 & 23.1 & 23.3 & $1815 \quad 8$ & 5.00 \\
\hline Mean litter size & 4.8 & 4.9 & 5.4 & $1815 \quad 8$ & 0.74 \\
\hline
\end{tabular}

${ }^{*} p<.05 . \quad+p<.001$. 
Thirty-one of the 40 females that mated but did not deliver a litter were pseudopregnant. Thus $78 \%$ of the females displayed an interruption of regular cycling as a result of mating; only 9 females returned to estrus in 7 days or less.

Effects of mating order on pregnancy are presented in Table 1. The numbers of females delivering litters were 18,15 , and 8 for the three ordinal positions, respectively. If ordinal positions in which males neither copulated nor ejaculated with a female are included as zeros, rather than treated as missing data, there is a significant difference as a function of ordinal position. However, this was entirely due to males that failed to copulate or ejaculate. An analysis using the 22 males that copulated with all $3 \mathrm{fe}-$ males yielded no significant difference. For the males that ejaculated with all 3 females, 7 of the 11 females mating in each of the three ordinal positions delivered litters.

There were no significant differences as a function of mating order with respect to gestation period, litter size, or the number of days to return to estrus in nonpregnant females.

\section{DISCUSSION}

These results clearly reveal again that male capacity is quite limited. When permitted to mate for $1 \mathrm{~h}$ with each of 3 successive females, only 11 of 30 males ejaculated with all 3 . Furthermore, the opportunity to resume copulating with novel females was substantial; males that failed to copulate were allowed a mean of over $1 \mathrm{~h}$ with 1-4 females and still failed to mate. Only 4 males impregnated 3 females each. Despite these limitations, males that did copulate with third females were essentially as effective at impregnating them as were rested males.

Although exact mating patterns in the field are not known, it is likely that limitations on male capacity are sometimes functional (see Dewsbury \& Sawrey, 1984). Females in the field are sometimes multiply mated (Birdsall \& Nash, 1973); there is extensvie home-range overlap of opposite-sexed animals (Metzgar, 1979); dominant males achieved a disproportionate number of copulations (Dewsbury, 1981); and females appear to synchronize estrous cycles (Bronson \& Marsden, 1964). These facts make it appear likely that at least some males, probably those that are dominant, have access to several females within relatively short time periods.

One difficulty in detecting an effect of depletion on pregnancy in the present study was the relatively low pregnancy rate for first females. Although all mice were of proven fertility and the first females received a mean of 4.9 ejaculations, only $60 \%$ delivered litters. This rate is not atypical for this species with females in cycling estrus (e.g., Dewsbury, 1984). That this is not a function of husbandry conditions is suggested by the high rate when females are in postpartum estrus (Dewsbury, 1979b).

From a female's perspective, it was best to mate with a male that had not recently mated; a female's best chances of becoming pregnant occurred when she was the first female with the rested male. It appears to be adaptive for females to prefer unmated males, as has been shown for several species (e.g., Huck, Lisk, Parente, \& Principato, 1986; Nakatsuru \& Kramer, 1982). However, for the deer mice in the present study, the difference in ordinal position related to the failure of males to copulate and ejaculate late in episodes, rather than to their failure to inseminate females as effectively as they did early in episodes. The risk to a female was especially great when she mated with a male and received long intromissions with no ejaculations. Most females that mated and failed to become pregnant became pseudopregnant. Such females lose approximately 10 days of their reproductive lives (approximately 14 days to return to estrus vs. 4 days for pregnant females). In the field, this would represent a significant loss to females of short-lived species such as deer mice.
From the male perspective, there was no detectable loss in potency, as long as the males continued to ejaculate. This is in spite of the fact that sperm counts decrease over successive series so that the sixth ejaculation contains only approximately one-quarter as many sperm as the first (Dewsbury \& Sawrey, 1984). A lack of decrements in potency over successive ejaculations has also been found in other species (e.g., Adams \& Singh, 1981; Allison, 1978; Markow, 1985). In house mice it has been found that potency is reduced only when epididymal sperm counts drop to below $10 \%$ of normal (Searle \& Beechey, 1974).

These data, obtained using a more powerful method, supplement and support earlier work showing no decrease in the potency of successive single ejaculates in deer mice (Dewsbury \& Sawrey, 1984). It is likely that deer mice differ in this respect from species such as laboratory rats and golden hamsters, in which such decreases have been found. Male deer mice, but not male rats and hamsters, appear to cease mating before depletion-related decrements in potency become detectable. As additional data from other species become available, it should be possible to relate these differences to ecological and other correlates.

\section{REFERENCES}

Adams, C. E., \& Singh, M. M. (1981). Semen characteristics and fertility of rabbits subjected to exhaustive use. Laboratory Animals, 15, 157-161.

Allison, A. J. (1978). Flock mating in sheep: IV. Effect of number of ewes per ram on ejaculate characteristics and libido during the mating period. New Zealand Journal of Agricultural Research, 21, 187-195.

Austin, D. J., \& DewsBury, D. A. (1986). Reproductive capacity of male laboratory rats. Physiology \& Behavior, 37, 627-632.

BaKsT, M. R., \& CECIL, H. C. (1981). Changes in the characteristics of turkey ejaculated semen and ductus deferens semen with repeated ejaculation. Reproduction, Nutrition, \& Development, 21, 1095-1103.

BirdSAll, D. A., \& NASH, D. (1973). Occurrence of successful multiple insemination of females in natural populations of deer mice (Peromyscus maniculatus). Evolution, 27, 106-110.

Bronson, F. H., \& MARSDEN, H. M. (1964). Male-induced synchrony of estrus in deermice. General \& Comparative Endocrinology, 4, 634-637.

DARWIN, C. (1871). The descent of man and selection in relation to sex. New York: Appleton.

DawkIns, R. (1976). The selfish gene. Oxford: Oxford University Press.

Dewsbury, D. A.(1979a). Copulatory behavior of deer mice (Peromyscus maniculatus): I. Normative data, subspecific differences, and effects of cross-fostering. Journal of Comparative \& Physiological Psychology, 93, 151-160.

Dewsbury, D. A.(1979b). Copulatory behavior of deer mice (Peromyscus maniculatus): III. Effects on pregnancy initiation. Journal of Comparative \& Physiological Psychology, 93, 178-188.

DewSBURY, D. A.(1981). Social dominance, copulatory behavior, and differential reproduction in deer mice (Peromyscus maniculatus). Journal of Comparative \& Physiological Psychology, 95, 880-895.

Dewsbury, D. A.(1982). Ejaculate cost and male choice. American Naturalist, 119, 601-610.

DewsBury, D. A.(1983). Recovery from sexual satiety in deer mice (Peromyscus maniculatus bairdi). Journal of Comparative Psychology, 97, 34-42.

Dewsbury, D. A.(1984). Studies of the effects of variation at the transferrin locus on reproductive processes in deer mice. Acta Theriologica, 30, 227-240.

Dewsbury, D. A., \& SAWreY, D. K. (1984). Male capacity as related to sperm production, pregnancy initiation, and sperm competition in deer mice (Peromyscus maniculatus). Behavioral Ecology \& Sociobiology, 16, 37-47.

Halliday, T., \& Houston, A. (1978). The newt as an honest salesman. Animal Behaviour, 26, 1273-1274.

HuCK, U. W., \& LisK, R. D. (1985a). Determinants of mating success in the golden hamster (Mesocricetus auratus): I. Male capacity. Journal of Comparative Psychology, 99, 98-107. 
Huck, U. W., \& Lisk, R. D. (1985b). Determinants of mating success in the golden hamster (Mesocricetus auratus): II. Pregnancy initiation. Journal of Comparative Psychology, 99, 231-239.

Huck, U. W., Lisk, R. D., Parente, E. J., \& Principato, D. E. (1986). Determinants of mating success in the golden hamster (Mesocricetus auratus): III. Female acceptance of multiple mating partners. Journal of Comparative Psychology, 100, 128-136.

MARKOW, T. A. (1985). A comparative investigation of the mating system of Drosophila hydei. Animal Behaviour, 33, 775-781.

Metzgar, L. H. (1979). Dispersion patterns in a Peromyscus population. Journal of Mammalogy, 60, 129-145.
NAKATSURU, K., \& Kramer, D. L. (1982). Is sperm cheap? Limited male fertility and female choice in the lemon tetra (Pisces, Characidae). Science, 216, 753-755.

SeARLe, A. G., \& Beechey, C. V. (1974). Sperm count, egg-fertilization and dominant lethality after $\mathrm{x}$-irradiation of mice. Mutation Research, 22, 63-72.

TONER, J. P., \& ADLER, N. T. (1985). Potency of rat ejaculations varies with their order and with male age. Physiology \& Behavior, 35, 113-115.

(Manuscript received for publication September 19, 1987.) 